\title{
Toll-like receptor-4 modulation for cancer immunotherapy
}

\author{
Shanjana Awasthi * \\ Department of Pharmaceutical Sciences, University of Oklahoma Health Sciences Center, Oklahoma City, OK, USA \\ ${ }^{*}$ Correspondence: shanjana-awasthi@ouhsc.edu \\ Edited by: \\ Anton G. Kutikhin, Russian Academy of Medical Sciences, Russia \\ Reviewed by: \\ Justin Lathia, Cleveland Clinic Lerner Research Institute, USA
}

Keywords: toll-like receptor 4, inflammation, immune response, cancer, immunomodulation

\section{INTRODUCTION}

Toll-like receptors (TLRs) are evolutionarily conserved pattern recognition molecules. Since the discovery of the Toll pathway cascade $(1,2)$, our knowledge about the structure, function, and mechanics of TLRs in infectious and inflammatory conditions has increased remarkably. The role of TLR4 as a pathogenpattern recognition receptor has been studied extensively. We now know that TLR4 recognizes pathogen-associated molecular patterns (PAMPs), such as Gramnegative bacterial lipopolysaccharide (LPS) and endogenous damage-associated molecular patterns (DAMPs) like fibronectin and hyaluronan, which are released during infectious and non-infectious inflammatory conditions. Some chronic infections and inflammatory conditions are known to promote carcinogenesis. For example, Helicobacter pylori (3) and viral hepatitis (4) infections lead to gastric and liver cancers, respectively. Also, in inflammatory bowel disease, non-infectious inflammation promotes the development of colorectal cancer (5). Evidence from recent reports suggests that increased expression and activity of TLR4 in chronic infectious and inflammatory conditions is associated with cancer progression (6-8). At the same time, additional studies suggest the protective role of TLR4 in cancer (9-14). The role of TLR4 in cancer has only recently been studied. This review article provides a brief summary of the current understanding of TLR4-signaling, its pro- and anticancer effects, and the therapeutic potential of TLR4 immunomodulation in the prevention and treatment of cancer.

\section{LIGAND RECOGNITION AND ACTIVATION OF TLR4}

Activation of TLR4 and downstream intracellular signaling involves interaction with
TLR4 ligands, dimerization, and assembly of the TLR4-complex with its adaptor and co-receptor molecules. Our understanding of TLR4-signaling is based on the results of the studies focused on the interaction of TLR4 with Escherichia coli-derived LPS. It has been demonstrated that the LPS binding protein (LBP) transfers the LPS to CD14 that is present in soluble form or linked to the cell surface by a glycosylphosphatidylinositol anchor. LPS is then transferred from CD14 to the myeloid differentiation (MD2) protein (6). CD14 and MD2 do not have cytoplasmic tails and are unable to transduce signals on their own. The fatty acyl chains of lipid A of LPS are integrated into the hydrophobic pocket of MD2, and negatively charged phosphate groups on the diglucosamine backbone of lipid A interact with the charged residues at the opening of the binding pocket of MD2. The LPS-MD2 interaction with TLR4 then causes dimerization of the TLR4-MD2 in 1:1 ratio and assembly of TLR4-MD2-LPS complex. The crystal structure of human TLR4-MD2-LPS complex shows the formation of an " $m$ "shaped oligomer made up of two molecules of TLR4 and two molecules of MD2 (15). Figure $1 \mathrm{~A}$ provides a pictorial representation of the steps involved in the formation of the TLR4-MD2-LPS complex.

\section{TLR4-SIGNALING AND HOST DEFENSE MECHANISMS}

After the TLR4-MD2-LPS complex formation, TLR4 signals through myeloid differentiation primary response protein (MYD88)-dependent and Toll/IL$1 \mathrm{R}$ domain-containing adaptor inducing interferon-beta (TRIF)-dependent pathways. Dimerization of TLR4-MD2 recruits TIRAP (Toll/IL-1R domain-containing adaptor protein) and MYD88, leading to intracellular signaling, activation of transcription factors, and production of pro-inflammatory cytokines. TLR4 also recruits additional proteins, TRIF-related adaptor molecule (TRAM) and TRIF, and induces production of type I interferons. Type I interferons are associated with immune responses elicited by $\mathrm{T}$ and $\mathrm{NK}$ cells, important effector cells of adaptive immunity (16). During the late phase of signaling, activation of TRIF can also induce NF- $\kappa B$ transcription factor.

Immune response to any pathogenic stimuli includes activation of innate immunity, inflammation, and adaptive immunity. TLR4-signaling can eventually lead to a multitude of cellular effects (17). It is well-established that during the innate phase of immune response, TLR4 recognizes its ligands (pathogens, PAMPs, or DAMPs), and facilitates their uptake, intracellular processing, and the inflammatory response (18-21). After the TLR4 ligands are internalized and processed, the antigens are loaded onto the major histocompatibility complex (MHC) molecules for presentation to naïve lymphocytes. Published reports support the role of TLR4 in antigen-presentation and activation of cellular and humoral immune responses (22-25). Figure 1B summarizes the recognition of ligands by TLR4, TLR4-signaling through MYD88 and TRIF, and its role in inflammation and antigen-presentation. Thus, it is apparent that TLR4 is involved directly or indirectly with different arms of the host defense system $(21,26)$.

\section{TLR4 AND CANCER}

TLR4 is associated with cancer in several ways. Diverse cell lines and tissue samples derived from patients with head and neck, esophageal, gastric, colorectal, liver, pancreatic, skin, breast, ovarian, cervical, and breast cancer have been shown to express increased amounts of TLR4 (27). 
A

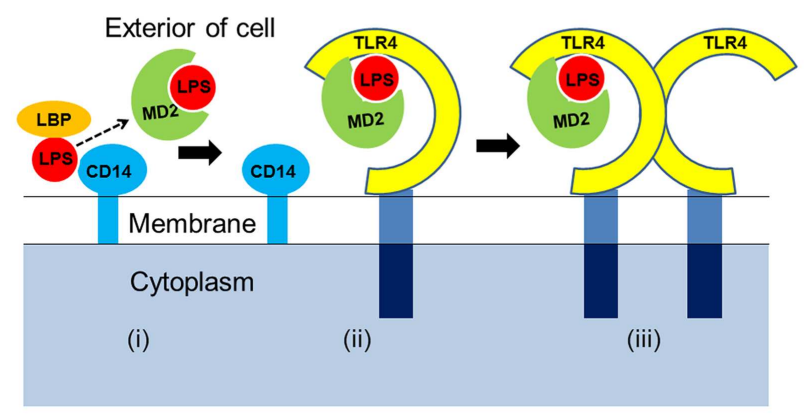

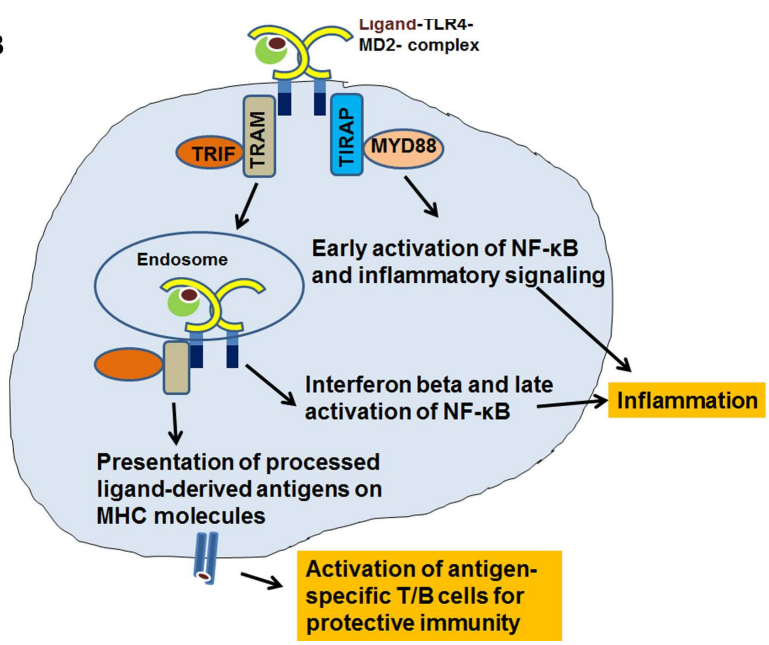

FIGURE 1 | (A) A cartoon showing assembly of TLR4-MD2-LPS complex. The LPS is transferred to MD2 (i) Conjugation of LPS-MD2 with TLR4 (ii) then leads to dimerization of TLR4-MD2, and formation of TLR4-MD2-LPS complex (iii). (B) After the recognition of ligand and assembly of TLR4-complex, co-receptors: TIRAP, MYD88, TRAM and TRIF, are recruited at the intracellular level for activation of TLR4-signaling resulting into antigen-specific immune responses.

Constitutive expression of some TLR4 genetic variants has also been linked to cancer (28-32). These characteristics are therefore being considered for their prognostic value in cancer treatment (32-34). In these scenarios of established cancer, TLR4 facilitates an environment that is suitable for continued cancer cell proliferation. Pro-cancer mechanisms could include the evasion of cancer cells from immune surveillance (35-38).

Persistent activation of TLR4-induced inflammatory signaling in chronic inflammatory conditions can also contribute to carcinogenesis (39). Experimental evidence suggests that cancer cell migration and invasion are induced by triggering of TLR4-NF- $\kappa \mathrm{B}$ under inflammatory conditions (40-42). LPS-induced TLR4signaling also promotes cancer cell survival and proliferation in hepatocellular carcinoma $(43,44)$. Moreover, the blockade of TLR4 by siRNA and NF- $\mathrm{B}$ inhibitors decreases the invasive ability of cancer cells. Correspondingly, TLR4 silencing has been shown to decrease tumor burden in a murine model of colorectal metastasis and hepatic steatosis (45).

At the same time, published data suggest that TLR4 is required for protective immune response and killing of cancer cells. For example, TLR4-deficient mice developed more tumors after oral gavage with polyaromatic hydrocarbon 7,12-dimethylbenz(a)anthracene than did wild-type mice (46). Similarly, silencing of TLR4 increased breast cancer metastasis (47). Although mechanism is not fully understood, TLR4 can induce an efficient cancer antigen-specific cytotoxic $\mathrm{T}$ cell immune response (48). The cytotoxic $\mathrm{T}$ cells will eventually kill the cancer cells. The dynamics of the TLR4-induced immune parameters in the tumor microenvironment could be complex, and is not well studied. It is possible that TLR4 exerts pro- or anti-cancer effects, depending on the prevailing conditions in the tissue microenvironment during different phases of cancer development or metastasis.

\section{CURRENTLY AVAILABLE TLR4 IMMUNOMODULATORY AGENTS}

A number of immunomodulators, which target TLR4 have been developed. These modulators (antagonists or agonists) have been grouped based on their binding and sequestration of LPS, antagonizing LBP and CD14/LPS interactions, and targeting of MD2, TLR4-MD2, or TLR4.

Monophosphoryl lipid A (MPLA), a chemically modified derivative of LPS, is less toxic, and retains most of the immunostimulatory activity of LPS. MPLA serves as a TLR4 agonist. It has been approved in Europe as a vaccine adjuvant, and is a component of Hepatitis B and Human Papillomavirus Virus vaccines (49). Another lipid-based agonist, E6020 (Eisai/Sanofi Pasteur), has also been developed as a vaccine adjuvant $(50,51)$. Other lipid molecules are being investigated for their potential to target the CD14-LPS interaction and antagonistic activity (52). Eritoran (E5564), developed by Eisai (Tokyo, Japan), directly binds to the hydrophobic pocket of MD2, competitively inhibits LPS from binding to MD2, and prevents the dimerization of TLR4, as well as TLR4-signaling (53). TAK-242, a cyclohexene derivative, was later developed by Takeda Pharmaceuticals (Tokyo, Japan) to target the TLR4 on the cellular membrane. Both TAK-242 and Eritoran (E5564) have been investigated in clinical trials as possible treatments for sepsis (54). Ibudilast (AV4II), a TLR4 antagonist, has been shown to suppress proinflammatory cytokines, such as TNF- $\alpha$ and IL-6, in neuroinflammation (55). Antibodies that target TLR4, NI-0101, and IA6 (NovImmune, Geneva, Switzerland), are being investigated for the treatment of acute and chronic inflammation. Glucopyranosyl lipid adjuvant-stable emulsion (GLA-SE; Immune design, Seattle, WA, USA), is also being studied (http:// www.clinicaltrials.gov). Although Eritoran and TAK-242 did not show efficacy for treatment of sepsis, a complicated clinical problem, studies with these modulators have clearly improved our understanding of the structural aspects of TLR4-complex formation and signaling. 


\section{POTENTIAL OF TLR4 IMMUNOMODULATION FOR THE PREVENTION OR TREATMENT OF CANCER}

Agents with TLR4-antagonistic activity have been shown to reduce inflammationinduced carcinogenesis by suppressing the TLR4-induced NF- $\mathrm{B}$ signaling. Curcumin, the main constituent of the spice turmeric, has been found to most likely bind to MD2, thus competing with LPS (56). A number of synthetic curcuminoids, such as EF24, have also been found to have anti-inflammatory activity (57-60). Our lab recently developed TLR4-interacting surfactant protein-A (SP-A) peptide, called SPA4, which binds to TLR4 protein in complex with MD2, and is effective therapeutically in cell culture systems and in a mouse model $(61,62)$. In the initial studies, our results showed that the TLR4interacting SPA4 peptide suppresses LPSTLR4-induced migration and invasion of colon cancer cells (63). More studies are warranted to understand the mechanism of SPA4 peptide activity. Other agents, including resveratrol (64), NI-0101 antibody (65), and paeoniflorin (66), have also shown suppression of inflammation-induced carcinogenesis.

While TLR4 antagonists could help reduce progression of inflammationinduced carcinogenesis or metastasis, TLR4 agonists have been shown to induce antitumor immunity in patients and models of established cancer. Lipid A-based TLR4 agonists, known as OM-174 and AS15, exhibit anti-cancer effects (67-70). Incorporation of the LPS and E6020 to Paclitaxel, whole cell tumor cell vector, and Trastuzumab improved the antitumor immunity in mouse models (7173). Picibanil (OK-432) targets both TLR2 and TLR4 and suppresses cancer (74). Vacchelli et al. recently published a detailed review of the ongoing clinical trials on TLR modulators, including TLR4 agonists. While the results from the ongoing clinical trials are pending, there is currently a significant emphasis on the design and development of novel TLR4 immunomodulators.

Although the potential of TLR4 immunomodulation for cancer immunotherapy has not been explored extensively, initial results from pre-clinical and clinical studies look promising. It is reasonable to imagine a TLR4 immunomodulatory agent that reduces inflammatory response, but promotes anti-tumor immunity. This could be beneficial in controlling multiple stages of cancer. Comprehensive studies are therefore needed to understand the mechanism of action of TLR4 immunomodulators in appropriate in vitro and in vivo models of cancer.

\section{INFORMATION ABOUT PATENT APPLICATIONS PERTAINING TO TLR4 IMMUNOMODULATION BY SURFACTANT PROTEIN-A (SP-A) DERIVED PEPTIDES}

Patent applications have been filed on the concept of TLR4-interacting SP-A peptides for immunomodulation with United States Patent and Trademark Office (USPTO), World Intellectual Property Organization, European, Canadian, and Australian Patent agencies. A patent was recently issued by the USPTO (US 8,623,832; Inventor: Shanjana Awasthi; Assigned to the Board of Regents of the University of Oklahoma, Norman, Oklahoma).

\section{REFERENCES}

1. Rock FL, Hardiman G, Timans JC, Kastelein RA, Bazan JF. A family of human receptors structurally related to Drosophila Toll. Proc Natl Acad Sci U S A (1998) 95(2):588-93. doi:10.1073/pnas.95. 2.588

2. Poltorak A, He X, Smirnova I, Liu MY, Van Huffel C, Du X, et al. Defective LPS signaling in $\mathrm{C} 3 \mathrm{H} / \mathrm{HeJ}$ and $\mathrm{C} 57 \mathrm{BL} / 10 \mathrm{ScCr}$ mice: mutations in TLR4 gene. Science (1998) 282(5396):2085-8. doi: 10.1126/science.282.5396.2085

3. Wang F, Meng W, Wang B, Qiao L. Helicobacter pylori-induced gastric inflammation and gastric cancer. Cancer Lett (2014) 345(2):196-202. doi:10.1016/j.canlet.2013.08.016

4. Xu JH, Fu JJ, Wang XL, Zhu JY, Ye XH, Chen SD. Hepatitis B or C viral infection and risk of pancreatic cancer: a meta-analysis of observational studies. World J Gastroenterol (2013) 19(26):4234-41. doi:10.3748/wjg.v19.i26.4234

5. Rogler G. Chronic ulcerative colitis and colorectal cancer. Cancer Lett (2014) 345(2):235-41. doi:10. 1016/j.canlet.2013.07.032

6. Oblak A, Jerala R. Toll-like receptor 4 activation in cancer progression and therapy. Clin Dev Immunol (2011) 2011:609579. doi:10.1155/2011/609579

7. Pradere JP, Dapito DH, Schwabe RF. The Yin and Yang of Toll-like receptors in cancer. Oncogene (2013) 33(27):3485-95. doi:10.1038/onc.2013.302

8. Wolska A, Lech-Maranda E, Robak T. Toll-like receptors and their role in carcinogenesis and anti-tumor treatment. Cell Mol Biol Lett (2009) 14(2):248-72. doi:10.2478/s11658-008-0048-z

9. Higgins SC, Jarnicki AG, Lavelle EC, Mills KH. TLR4 mediates vaccine-induced protective cellular immunity to Bordetella pertussis: role of IL-17-producing $\mathrm{T}$ cells. $\mathrm{J}$ Immunol (2006) 177(11):7980-9. doi:10.4049/jimmunol. 177.11.7980

10. Kerepesi LA, Hess JA, Leon O, Nolan TJ, Schad GA, Abraham D. Toll-like receptor 4 (TLR4) is required for protective immunity to larval Strongyloides stercoralis in mice. Microbes Infect (2007) 9(1):28-34. doi:10.1016/j.micinf.2006.10.003

11. Imado T, Iwasaki T, Kitano S, Satake A, Kuroiwa $\mathrm{T}$, Tsunemi S, et al. The protective role of host Toll-like receptor- 4 in acute graft-versus-host disease. Transplantation (2010) 90(10):1063-70. doi: 10.1097/TP.0b013e3181f86947

12. Jordan JM, Woods ME, Olano J, Walker DH. The absence of Toll-like receptor 4 signaling in $\mathrm{C} 3 \mathrm{H} / \mathrm{HeJ}$ mice predisposes them to overwhelming rickettsial infection and decreased protective Th1 responses. Infect Immun (2008) 76(8):3717-24. doi:10.1128/IAI.00311-08

13. Supajatura V, Ushio H, Nakao A, Okumura K, Ra C, Ogawa H. Protective roles of mast cells against enterobacterial infection are mediated by Tolllike receptor 4. J Immunol (2001) 167(4):2250-6. doi:10.4049/jimmunol.167.4.2250

14. Nunez NG, Andreani V, Crespo MI, Nocera DA, Breser ML, Moron G, et al. IFNbeta produced by TLR4-activated tumor cells is involved in improving the antitumoral immune response. Cancer Res (2012) 72(3):592-603. doi:10.1158/ 0008-5472.CAN-11-0534

15. Park BS, Lee JO. Recognition of lipopolysaccharide pattern by TLR 4 complexes. Exp Mol Med (2013) 45:e66. doi:10.1038/emm.2013.97

16. Le Bon A, Tough DF. Links between innate and adaptive immunity via type I interferon. Curr Opin Immunol (2002) 14(4):432-6. doi:10.1016/S09527915(02)00354-0

17. Lu YC, Yeh WC, Ohashi PS. LPS/TLR4 signal transduction pathway. Cytokine (2008) 42(2):145-51. doi:10.1016/j.cyto.2008.01.006

18. Chen YJ, Hsieh MY, Chang MY, Chen HC, Jan MS, Maa MC, et al. Eps8 protein facilitates phagocytosis by increasing TLR4-MyD88 protein interaction in lipopolysaccharide-stimulated macrophages. $J$ Biol Chem (2012) 287(22):18806-19. doi:10.1074/ jbc.M112.340935

19. Jain V, Halle A, Halmen KA, Lien E, CharrelDennis M, Ram S, et al. Phagocytosis and intracellular killing of MD-2 opsonized gramnegative bacteria depend on TLR4 signaling. Blood (2008) 111(9):4637-45. doi:10.1182/blood-200711-126862

20. Neal MD, Leaphart C, Levy R, Prince J, Billiar TR, Watkins S, et al. Enterocyte TLR4 mediates phagocytosis and translocation of bacteria across the intestinal barrier. J Immunol (2006) 176(5):3070-9. doi:10.4049/jimmunol.176.5.3070

21. Underhill DM, Goodridge HS. Information processing during phagocytosis. Nat Rev Immunol (2012) 12(7):492-502. doi:10.1038/nri3244

22. Ni Gabhann J, Spence S, Wynne C, Smith S, Byrne JC, Coffey B, et al. Defects in acute responses to TLR4 in Btk-deficient mice result in impaired dendritic cell-induced IFN-gamma production by natural killer cells. Clin Immunol (2012) 142(3):373-82. doi:10.1016/j.clim.2011.12.009

23. Wagner CS, Cresswell P. TLR and nucleotidebinding oligomerization domain-like receptor signals differentially regulate exogenous antigen 
presentation. J Immunol (2012) 188(2):686-93. doi:10.4049/jimmunol.1102214

24. Pufnock JS, Cigal M, Rolczynski LS, AndersenNissen E, Wolfl M, McElrath MJ, et al. Priming CD8+ $\mathrm{T}$ cells with dendritic cells matured using TLR4 and TLR7/8 ligands together enhances generation of CD8+ $\mathrm{T}$ cells retaining CD28. Blood (2011) 117(24):6542-51. doi:10. 1182/blood-2010-11-317966

25. Park HJ, Qin H, Cha SC, Sharma R, Chung $\mathrm{Y}$, Schluns KS, et al. Induction of TLR4dependent CD8+ $\mathrm{T}$ cell immunity by murine beta-defensin2 fusion protein vaccines. Vaccine (2011) 29(18):3476-82. doi:10.1016/j.vaccine. 2011.02 .061

26. Siegemund S, Sauer K. Balancing pro- and anti-inflammatory TLR4 signaling. Nat Immunol (2012) 13(11):1031-3. doi:10.1038/ni.2452

27. Mai CW, Kang YB, Pichika MR. Should a Tolllike receptor4 (TLR-4) agonist or antagonist be designed to treat cancer? TLR-4: its expression and effects in the ten most common cancers. Onco Targets Ther (2013) 6:1573-87. doi:10.2147/OTT. S50838

28. Stevens VL, Hsing AW, Talbot JT, Zheng SL, Sun $\mathrm{J}$, Chen J, et al. Genetic variation in the tolllike receptor gene cluster (TLR10-TLR1-TLR6) and prostate cancer risk. Int J Cancer (2008) 123(11):2644-50. doi:10.1002/ijc.23826

29. Zhang K, Zhou B, Wang Y, Rao L, Zhang L. The TLR4 gene polymorphisms and susceptibility to cancer: a systematic review and meta-analysis. Eur J Cancer (2013) 49(4):946-54. doi:10.1016/j.ejca. 2012.09.022

30. Zou TH, Wang ZH, Fang JY. Positive association between Toll-like receptor 4 gene $+896 \mathrm{~A} / \mathrm{G}$ polymorphism and susceptibility to gastric carcinogenesis: a meta-analysis. Tumour Biol (2013) 34(4):2441-50. doi:10.1007/s13277-013-0795-y

31. Huang L, Yuan K, Liu J, Ren X, Dong X, Tian $\mathrm{W}$, et al. Polymorphisms of the TLR4 gene and risk of gastric cancer. Gene (2014) 537(1):46-50. doi:10.1016/j.gene.2013.12.030

32. Yang CX, Li CY, Feng W. Toll-like receptor 4 genetic variants and prognosis of breast cancer. Tissue Antigens (2013) 81(4):221-6. doi:10.1111/tan. 12096

33. Slattery ML, Herrick JS, Bondurant KL, Wolff RK. Toll-like receptor genes and their association with colon and rectal cancer development and prognosis. Int J Cancer (2012) 130(12):2974-80. doi:10.1002/ijc.26314

34. Ehsan N, Murad S, Ashiq T, Mansoor MU, Gul S, Khalid S, et al. Significant correlation of TLR4 expression with the clinicopathological features of invasive ductal carcinoma of the breast. Tumour Biol (2013) 34(2):1053-9. doi:10.1007/s13277013-0645-y

35. Wang L, Zhao Y, Qian J, Sun L, Lu Y, Li H, et al. Toll-like receptor-4 signaling in mantle cell lymphoma: effects on tumor growth and immune evasion. Cancer (2013) 119(4):782-91. doi:10.1002/ cncr.27792

36. Huang B, Zhao J, Li H, He KL, Chen Y, Chen $\mathrm{SH}$, et al. Toll-like receptors on tumor cells facilitate evasion of immune surveillance. Cancer Res (2005) 65(12):5009-14. doi:10.1158/0008-5472. CAN-05-0784
37. Fu HY, Li C, Yang W, Gai XD, Jia T, Lei YM, et al. FOXP3 and TLR4 protein expression are correlated in non-small cell lung cancer: implications for tumor progression and escape. Acta Histochem (2013) 115(2):151-7. doi:10.1016/j.acthis.2012.06 002

38. Tang X, Zhu Y. TLR4 signaling promotes immune escape of human colon cancer cells by inducing immunosuppressive cytokines and apoptosis resistance. Oncol Res (2012) 20(1):15-24. doi:10.3727/ $096504012 X 13425470196092$

39. Fukata M, Shang L, Santaolalla R, Sotolongo J, Pastorini C, Espana C, et al. Constitutive activation of epithelial TLR4 augments inflammatory responses to mucosal injury and drives colitis-associated tumorigenesis. Inflamm Bowe Dis (2011) 17(7):1464-73. doi:10.1002/ibd.21527

40. Ikebe M, Kitaura Y, Nakamura M, Tanaka H, Yamasaki A, Nagai S, et al. Lipopolysaccharide (LPS) increases the invasive ability of pancreatic cancer cells through the TLR4/MyD88 signaling pathway. J Surg Oncol (2009) 100(8):725-31. doi:10.1002/jso.21392

41. Liao SJ, Zhou YH, Yuan Y, Li D, Wu FH, Wang Q, et al. Triggering of Toll-like receptor 4 on metastatic breast cancer cells promotes alphavbeta3mediated adhesion and invasive migration. Breast Cancer Res Treat (2012) 133(3):853-63. doi:10. 1007/s10549-011-1844-0

42. Kelsh RM, McKeown-Longo PJ. Topographical changes in extracellular matrix: activation of TLR4 signaling and solid tumor progression. Trends Cancer Res (2013) 9:1-13.

43. Wang L, Zhu R, Huang Z, Li H, Zhu H. Lipopolysaccharide-induced toll-like receptor 4 signaling in cancer cells promotes cell survival and proliferation in hepatocellular carcinoma. Dig Dis Sci (2013) 58(8):2223-36. doi:10.1007/s10620013-2745-3

44. Yuan X, Zhou Y, Wang W, Li J, Xie G, Zhao Y, et al. Activation of TLR4 signaling promotes gastric cancer progression by inducing mitochondrial ROS production. Cell Death Dis (2013) 4:e794. doi:10.1038/cddis.2013.334

45. Earl TM, Nicoud IB, Pierce JM, Wright JP, Majoras NE, Rubin JE, et al. Silencing of TLR4 decreases liver tumor burden in a murine model of colorectal metastasis and hepatic steatosis. Ann Surg Oncol (2009) 16(4):1043-50. doi:10.1245/s10434009-0325-8

46. Naseemuddin M, Iqbal A, Nasti TH, Ghandhi JL, Kapadia AD, Yusuf N. Cell mediated immune responses through TLR4 prevents DMBA-induced mammary carcinogenesis in mice. Int $J$ Cancer (2012) 130(4):765-74. doi:10.1002/ijc.26100

47. Ahmed A, Wang JH, Redmond HP. Silencing of TLR4 increases tumor progression and lung metastasis in a murine model of breast cancer. Ann Surg Oncol (2013) 20(Suppl 3):S389-96. doi:10.1245/ s10434-012-2595-9

48. Fang H, Ang B, Xu X, Huang X, Wu Y, Sun $\mathrm{Y}$, et al. TLR4 is essential for dendritic cell activation and anti-tumor T-cell response enhancement by DAMPs released from chemically stressed cancer cells. Cell Mol Immunol (2014) 11(2):150-9. doi:10.1038/cmi.2013.59

49. Krieg AM. Toll-free vaccines? Nat Biotechnol (2007) 25(3):303-5. doi:10.1038/nbt0307-303
50. Ishizaka ST, Hawkins LD. E6020: a synthetic Tolllike receptor 4 agonist as a vaccine adjuvant. Expert Rev Vaccines (2007) 6(5):773-84. doi:10. 1586/14760584.6.5.773

51. Dumonteil E, Bottazzi ME, Zhan B, Heffernan MJ, Jones K, Valenzuela JG, et al. Accelerating the development of a therapeutic vaccine for human Chagas disease: rationale and prospects. Expert Rev Vaccines (2012) 11(9):1043-55. doi:10.1586/ erv.12.85

52. Piazza M, Rossini C, Della Fiorentina S, Pozzi C, Comelli F, Bettoni I, et al. Glycolipids and benzylammonium lipids as novel antisepsis agents: synthesis and biological characterization. J Med Chem (2009) 52(4):1209-13. doi:10.1021/ jm801333m

53. Hawkins LD, Ishizaka ST, McGuinness P, Zhang $\mathrm{H}$, Gavin W, DeCosta B, et al. A novel class of endotoxin receptor agonists with simplified structure, toll-like receptor 4-dependent immunostimulatory action, and adjuvant activity. J Pharmacol Exp Ther (2002) 300(2):655-61. doi:10.1124/jpet. 300.2.655

54. Savva A, Roger T. Targeting toll-like receptors: promising therapeutic strategies for the management of sepsis-associated pathology and infectious diseases. Front Immunol (2013) 4:387. doi:10.3389/ fimmu.2013.00387

55. Ledeboer A, Mahoney JH, Milligan ED, Martin D, Maier SF, Watkins LR. Spinal cord glia and interleukin-1 do not appear to mediate persistent allodynia induced by intramuscular acidic saline in rats. J Pain (2006) 7(10):757-67. doi:10.1016/j. jpain.2006.04.001

56. Gradisar H, Keber MM, Pristovsek P, Jerala R. MD2 as the target of curcumin in the inhibition of response to LPS. J Leukoc Biol (2007) 82(4):968-74. doi:10.1189/jlb.1206727

57. Hossain DM, Bhattacharyya S, Das T, Sa G. Curcumin: the multi-targeted therapy for cancer regression. Front Biosci (ScholEd) (2012) 4:335-55. doi:10.2741/S272

58. Anand P, Sundaram C, Jhurani S, Kunnumakkara AB, Aggarwal BB. Curcumin and cancer: an "oldage" disease with an "age-old" solution. Cancer Lett (2008) 267(1):133-64. doi:10.1016/j.canlet.2008. 03.025

59. Zhu HT, Bian C, Yuan JC, Chu WH, Xiang X, Chen $\mathrm{F}$, et al. Curcumin attenuates acute inflammatory injury by inhibiting the TLR4/MyD88/NF-kappaB signaling pathway in experimental traumatic brain injury. J Neuroinflammation (2014) 11:59. doi:10. 1186/1742-2094-11-59

60. Vilekar P, Awasthi S, Natarajan A, Anant S, Awasthi V. EF24 suppresses maturation and inflammatory response in dendritic cells. Int Immunol (2012) 24(7):455-64. doi:10.1093/intimm/dxr121

61. Ramani V, Madhusoodhanan R, Kosanke S, Awasthi S. A TLR4-interacting SPA4 peptide inhibits LPS-induced lung inflammation. Innate Immun (2013) 19(6):596-610. doi:10.1177/ 1753425912474851

62. Awasthi S, Brown K, King C, Awasthi V, Bondugula R. A toll-like receptor-4-interacting surfactant protein-A-derived peptide suppresses tumor necrosis factor-alpha release from mouse JAWS II dendritic cells. J Pharmacol Exp Ther (2011) 336(3):672-81. doi:10.1124/jpet.110.173765 
63. Madhusoodhanan R, Moriasi C, Ramani V, Anant S, Awasthi S. A TLR4-interacting peptide inhibits lipopolysaccharide-stimulated inflammatory responses, migration and invasion of colon cancer SW480 cells. Oncoimmunology (2012) 1(9):1495-506. doi:10.4161/onci.22089

64. Panaro MA, Carofiglio V, Acquafredda A, Cavallo P, Cianciulli A. Anti-inflammatory effects of resveratrol occur via inhibition of lipopolysaccharide-induced NF-kappaB activation in Caco-2 and SW480 human colon cancer cells. Br J Nutr (2012) 108(9):1623-32. doi:10.1017/S0007114511007227

65. Hodgkinson L. Digestive disease week 2010. Turning science into medicine - part 2. IDrugs (2010) 13(7):424-6.

66. Zhang J, Dou W, Zhang E, Sun A, Ding L, Wei $\mathrm{X}$, et al. Paeoniflorin abrogates DSS-induced colitis via a TLR4-dependent pathway. Am J Physiol Gastrointest Liver Physiol (2014) 306(1):G27-36. doi: 10.1152/ajpgi.00465.2012

67. Onier N, Hilpert S, Arnould L, Saint-Giorgio V, Davies JG, Jeannin JF, et al. Cure of colon cancer metastasis in rats with the new lipid A OM 174. Apoptosis of tumor cells and immunization of rats. Clin Exp Metastasis (1999) 17(4):299-306. doi:10.1023/A:1006663017149

68. Garay RP, Viens P, Bauer J, Normier G, Bardou M, Jeannin JF, et al. Cancer relapse under chemotherapy: why TLR2/4 receptor agonists can help. Eur
J Pharmacol (2007) 563(1-3):1-17. doi:10.1016/j. ejphar.2007.02.018

69. Cluff CW. Monophosphoryl lipid A (MPL) as an adjuvant for anti-cancer vaccines: clinical results. Adv Exp Med Biol (2010) 667:111-23. doi:10.1007/ 978-1-4419-1603-7_10

70. Gerard C, Baudson N, Ory T, Louahed J. Tumor mouse model confirms MAGE-A3 cancer immunotherapeutic as an efficient inducer of longlasting anti-tumoral responses. PLoS One (2014) 9(5):e94883. doi:10.1371/journal.pone.0094883

71. Wang S, Astsaturov IA, Bingham CA, McCarthy $\mathrm{KM}$, von Mehren M, Xu W, et al. Effective antibody therapy induces host-protective antitumor immunity that is augmented by TLR4 agonist treatment. Cancer Immunol Immunother (2012) 61(1):49-61. doi:10.1007/s00262-011-1090-7

72. Davis MB, Vasquez-Dunddel D, Fu J, Albesiano E, Pardoll D, Kim YJ. Intratumoral administration of TLR4 agonist absorbed into a cellular vector improves antitumor responses. Clin Cancer Res (2011) 17(12):3984-92. doi:10.1158/10780432.CCR-10-3262

73. Roy A, Singh MS, Upadhyay P, Bhaskar S. Nanoparticle mediated co-delivery of paclitaxel and a TLR-4 agonist results in tumor regression and enhanced immune response in the tumor microenvironment of a mouse model. Int J Pharm (2013) 445(1-2):171-80. doi:10.1016/j.ijpharm. 2013.01.045
74. Akeda T, Yamanaka K, Kitagawa H, Kawabata E, Tsuda K, Kakeda M, et al. Intratumoral injection of OK-432 suppresses metastatic squamous cell carcinoma lesion inducing interferon-gamma and tumour necrosis factor-alpha. Clin Exp Dermatol (2012) 37(2):193-4. doi:10.1111/j.1365-2230. 2011.04151.x

Conflict of Interest Statement: The author declares that the research was conducted in the absence of any commercial or financial relationships that could be construed as a potential conflict of interest.

Received: 01 May 2014; accepted: 27 June 2014; published online: 25 July 2014.

Citation: Awasthi S (2014) Toll-like receptor-4 modulation for cancer immunotherapy. Front. Immunol. 5:328. doi: $10.3389 /$ fimmu.2014.00328

This article was submitted to Tumor Immunity, a section of the journal Frontiers in Immunology.

Copyright (c) 2014 Awasthi. This is an open-access article distributed under the terms of the Creative Commons Attribution License (CC BY). The use, distribution or reproduction in other forums is permitted, provided the original author(s) or licensor are credited and that the original publication in this journal is cited, in accordance with accepted academic practice. No use, distribution or reproduction is permitted which does not comply with these terms. 